\title{
Regional Energy Efficiency and Energy Saving Potential Analysis based on Slack-Based Measurement Approach
}

\author{
Miao $\mathrm{Hu}^{\mathrm{a}}$, Yage Wang ${ }^{\mathrm{b}}$ \\ SHU-UTS SILC Business School, Shanghai University, Shanghai 201800, China \\ ahumiao0723@163.com, bjacobwang123@gmail.com
}

Keywords: Energy efficiency; energy saving potential; SBM-DEA.

\begin{abstract}
This paper is committed to study Chinese provinces energy efficiency and energy saving potential, trying to provide decision-making information for China's emission reduction targets and policy formulation. For this purpose, this paper chooses slack-based measurement DEA model, improved to a standard linear programming style. In this model, Provincial wastewater, waste gas and industrial solid wastes are selected as undesirable output indicator to calculate energy efficiency and energy saving potential. The data sources from 2010 to 2012 Statistical Yearbook of China. Conclusion can be made that discrepancies of energy efficiencies are considerable among different provinces and China should start from central area to implement policies for energy saving.
\end{abstract}

\section{Introduction}

Since 1980s, China's economy has developed rapidly, which also leads to considerable energy consumption and waste emissions. The total consumption of energy China is considerable (3617.320 million tons of SCE) and ranks the first in the world. Economic development is also accompanied by production activities generating various waste gases, wastewater and other pollutants, which results in a variety of environmental pollution and ecological damage issues. Under this circumstance, Chinese various pollutants emissions are yet the highest in the world and far more than its own environmental capacity limits. According to UNEP ${ }^{[1]}$, China consumes about $21 \%$ of the world's energy, $11 \%$ of oil, $49 \%$ coal, and consumes $26 \%$ of the world's emissions of sulfur dioxide, $28 \%$ nitrogen oxides and $25 \%$ carbon dioxide. Due to China's vast territory, regional economic development, energy consumption, pollutant emission conditions are quite different. Therefore, China needs to implement various energy saving measures based on different condition of regions. Energy efficiency and waste reduction potential calculation for each region in China could improve the waste abatement situation and provide constructive suggestions for policy-makers.

\section{Literature Review}

Energy efficiency can be categorized into partial-factor energy efficiency and total-factor energy efficiency according to the numbers of selected input and output indexes. Partial-factor energy efficiency only considers one investment in energy. Patterson ${ }^{[2]}$ defines energy efficiency as the ratio of desired output and energy input in the production process of an economy. Due to the defects of partial-factor energy efficiency indicators, the researchers made improvements, putting forward total-factor energy efficiency. In addition to energy efficiency energy as inputs, total-factor energy efficiency considers other indicators like capital, labor, etc. as inputs. The typical model of parametric method is Stochastic Frontier Analysis (SFA), which first sets production function and strictly restrains the boundary shape of efficiency. However, Cooper and Tone ${ }^{[3]}$ point out that SFA calculate the efficiency through estimation of production function or cost function, thus, the deviation of its pre-set functions would affect result. Therefore, Charnels, Cooper and Rhodes ${ }^{[4]}$ firstly establish nonparametric method Data Envelopment Analysis (DEA), which can effectively avoid the model error only with input and output data without necessarily knowing specific form of the production frontier. Plenty of studies have begun to focus on the energy efficiency calculations of China's regions and industries using DEA. Hu and Wang ${ }^{[5]}$ calculate total-factor energy efficiency of 
China during 1995 to 2002 in 29 provinces based on DEA approach. Wang and Wei ${ }^{[6]}$ improve the traditional DEA model to calculate the energy efficiency and emission efficiency during 2006 to 2010 in 30 major cities in China. Some of the researches consider undesirable output. Zhang and Choi ${ }^{[7]}$ calculated three undesirable output (carbon dioxide, sulfur dioxide and chemical oxygen). Wei et al. ${ }^{[8]}$ explore the energy efficiency containing one undesirable output, carbon dioxide, in 29 China's provinces during 1995 to 2007 based on SBM-DEA. However, current researches still have some limitation in analyzing the pollutant reduction potential based on the energy efficiency analysis of undesirable output.

\section{Methodology}

Non-radial SBM-DEA model (Slack-Based Measurement Data Envelopment Analysis) is proposed by Tone ${ }^{[9]}$. Suppose that there are n decision-making units $D M U_{j}, \mathrm{~m}$ inputs $x_{i j}(i=1,2, \ldots, m)$, s desirable outputs $y_{r j}(r=1,2, \ldots, s)$ and k undesirable outputs $b_{u j}(u=1,2, \ldots, k)$, based on the method from Tone ${ }^{[9]}$, the model of SBM-DEA is:

$$
\begin{aligned}
& \min \rho=\frac{1-\frac{1}{m} \sum_{i=1}^{m} \frac{s_{i}^{x-}}{x_{i 0}}}{1+\underset{s+k}{1}\left(\sum_{r=1}^{s} s_{r}^{g_{r}+}+\sum_{u=1}^{k} b_{u 0}^{b-}\right)} \\
& x_{i 0}=\sum_{j=1}^{n} x_{i j} \lambda_{j}+s_{i}^{x-}, i=1,2, \ldots, m \\
& y_{r 0}=\sum_{j=1}^{n} y_{i j} \lambda_{j}-s_{r}^{g+}, r=1,2, \ldots, s \\
& b_{u 0}=\sum_{j=1}^{n} b_{u j} \lambda_{j}+s_{u}^{b-}, u=1,2, \ldots, k \\
& s_{i}^{x-}, s_{r}^{g^{+}}, s_{u}^{b-}, \lambda_{j} \geq 0 .
\end{aligned}
$$

Since the SBM-DEA is non-linear, in practice it is not easy to solve. Thus, it can be converted to linear programming, followed by Tone ${ }^{[9]}$. If we set the optimal solution of linear programming as $\left(\tau^{*}, t^{*}, \Lambda_{j}^{*}, S_{i}^{x^{-*}}, S_{r}^{g^{*}}, S_{u}^{b^{-*}}\right)$, then the optimal solution of SBM would be:

$$
\rho^{*}=\tau^{*}, \lambda_{j}^{*}=\frac{\Lambda_{j}^{*}}{t^{*}}, s_{i}^{x^{*}}=\frac{S_{i}^{x_{-*}^{*}}}{t^{*}}, s_{r}^{g^{*}}=\frac{S_{r}^{g^{*}}}{t^{*}}, s_{u}^{b^{*}}=\frac{S_{u}^{b^{*}}}{t^{*}}
$$

Definition 1: When $\rho^{*}=1$, the DMU is effective, with $s_{i}^{x^{-*}}=\mathbf{0}, s_{r}^{g t^{*}}=\mathbf{0}, s_{u}^{b-*}=\mathbf{0}$.

Definition 2: Reference set $R_{0}=\left\{j \mid \lambda_{j}^{*}>0\right\} .(j \in\{1,2, \ldots, n\})$

On the basis of previous studies, the author selects investment capital stock, labor, and energy consumption as input indicators. For the output indicators, the author selects GDP as desired output, and wastewater, waste gas (sulfur dioxide, nitrogen oxides and smoke and dust) and industrial solid wastes output as undesirable output. In this paper, the required data sources from 2010 to 2012 Statistical Yearbook of China. Notice that the Tibetan province will exclude them from our study due to unavailable data.

\section{Result and Discussion}

Descriptive Statistics of Input and Output Data. From 2010 to 2012, the average amount of energy consumed in China's provinces and cities reaches to 139.448 million tons of SCE; employment is 
4736.718 thousand people on average; capital stock averages at 960.528 billion RMB; GDP averages at 1703.578 billion RMB; the average wastewater discharged is 1756.024 million tons; the average waste gas discharged is 724.385 thousand tons; and the average industrial solid wastes discharged is 99.112 million tons. However, there are also significant differences among provinces with regard to each indicator. For example, Hainan consumes the least energy and has the least waste emissions - in 2010, energy consumption of Hainan is only 13.59 million tons of SCE and discharges 57.82 million tons of wastewater, 29 thousand ton of waste gas and 2.12 million tons of industrial solid wastes. In contrast, Shandong consumes the most energy and has huge amount of waste emissions-in 2012, energy consumption of Shandong is up to 138.99 million tons of SCE and discharges 4791 million tons of wastewater, 1.47488 million ton of waste gas and 183.426 million tons of industrial solid wastes.

Energy Efficiency Analysis. The author calculates the energy efficiency of China's provinces using MATLAB 2014a linear programming to solve SBM-DEA linear programming and obtain the result in Table 1 . The results show that the average values of the energy efficiency of China's provinces in 2010, 2011 and 2012 respectively are 0.68108, 0.68131 and 0.68102 , which is not high. It can be seen that during the three years energy efficiency of each province did not change much, with only small fluctuations, except Inner Mongolia whose energy efficiency dramatically rocketed to 1.00 in 2011. In these three years, there are five province whose averages have been 1.00, Beijing, Tianjin, Liaoning, Shanghai and Guangdong, which means that seven provinces is technological energy efficient, with minimum inputs and cost producing maximum desirable outputs. Furthermore, the energy efficiency of 1.00 means that the potential of their waste abatement have reached the status of saturation under current structure of the input-output without continuing abatement potential. Energy efficiency in Xinjiang is pretty low during the three years, only 0.38 averagely.

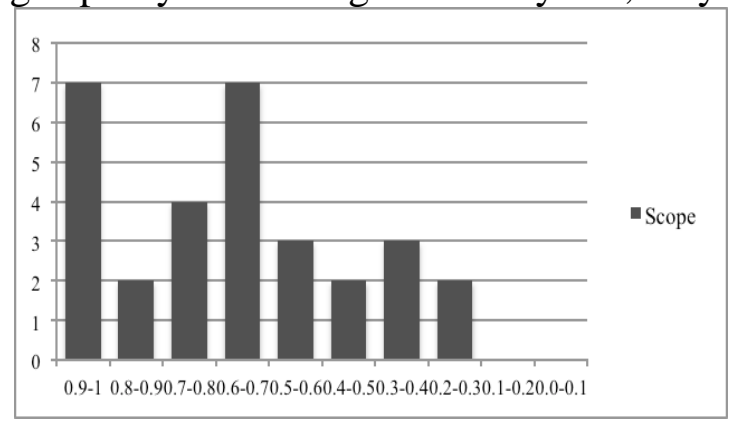

Fig. 1 Frequency Distribution Histogram of Energy Efficiency

The author then further calculates the frequency statistics of energy efficiency in 2012, revealed in frequency distribution histogram as Figure 1. Plenty of energy efficiency values are located in the interval from 0.30 to 0.70 , especially up to seven provinces in the scope from 0.60 to 0.70 . Although there are seven provinces in the range from 0.90 to 1.00, in fact the energy efficiency of six of them are 1.00, which means that in China there are only a few provincial energy efficiencies being greater than 0.80 and less than 1.00. Therefore, most of the provincial energy efficiencies are account of high values and those in middle; other averagely distributed in the second highest values and low values.

In order to study the differences among China's provinces and cities, according to traditional methods, the author divides them into eastern, central and western area. The eastern area includes 11 provinces (municipalities). Obviously the three areas' average energy efficiencies indicate significant differences, respectively 0.842 in eastern area, 0.668 in central area and 0.530 western. The energy efficiency calculation results show that not only does the eastern region show high level of economic development, but also its energy efficiency is much higher than in other areas, especially the western area. The reason is the eastern area is generally more developed in the light of regional economy and more advanced in technology, making the eastern region have more capital an advanced technology to obtain better energy input structure and energy processing technology to utilize energy more efficiently. In contrast, the western area are lagging behind, thus its energy use is not very effective. 
Table 1 Regional Energy Efficiency Based on SBM form 2010 to 2012

\begin{tabular}{|c|c|c|c|c|c|}
\hline \multirow{2}{*}{ Area } & \multirow{2}{*}{ Region } & \multicolumn{4}{|c|}{ Energy Efficiency } \\
\hline & & 2010 & 2011 & 2012 & Mean \\
\hline \multirow{11}{*}{ Eastern } & Beijing & 1.00000 & 1.00000 & 1.00000 & \multirow{11}{*}{0.84235} \\
\hline & Tianjin & 1.00000 & 1.00000 & 1.00000 & \\
\hline & Hebei & 0.48336 & 0.47747 & 0.46885 & \\
\hline & Liaoning & 0.57495 & 0.57828 & 0.59772 & \\
\hline & Shanghai & 1.00000 & 1.00000 & 1.00000 & \\
\hline & Jiangsu & 1.00000 & 1.00000 & 1.00000 & \\
\hline & Zhejiang & 0.90803 & 0.89467 & 0.88214 & \\
\hline & Fujian & 0.87859 & 0.78474 & 0.79344 & \\
\hline & Shandong & 0.73428 & 0.74187 & 0.66830 & \\
\hline & Guangdong & 1.00000 & 1.00000 & 1.00000 & \\
\hline & Hainan & 0.80811 & 0.75207 & 0.77083 & \\
\hline \multirow{8}{*}{ Central } & Shanxi & 0.35719 & 0.36844 & 0.33432 & \multirow{8}{*}{0.66795} \\
\hline & Jilin & 0.68166 & 0.68477 & 0.61993 & \\
\hline & Heilongjiang & 0.60225 & 0.59733 & 0.57274 & \\
\hline & Anhui & 0.83080 & 0.77478 & 0.80875 & \\
\hline & Jiangxi & 0.86971 & 0.90412 & 0.95495 & \\
\hline & Henan & 0.70287 & 0.63307 & 0.66802 & \\
\hline & Hubei & 0.68827 & 0.63381 & 0.67184 & \\
\hline & Hunan & 0.70329 & 0.66174 & 0.70612 & \\
\hline \multirow{11}{*}{ Western } & Inner Mongolia & 0.46919 & 1.00000 & 1.00000 & \multirow{11}{*}{0.52950} \\
\hline & Guangxi & 0.70670 & 0.76644 & 0.75987 & \\
\hline & Chongqing & 0.65829 & 0.63622 & 0.65208 & \\
\hline & Sichuan & 0.62675 & 0.59372 & 0.61922 & \\
\hline & Guizhou & 0.36733 & 0.34647 & 0.37021 & \\
\hline & Yunnan & 0.54345 & 0.52368 & 0.52731 & \\
\hline & Shaanxi & 0.74372 & 0.69401 & 0.65434 & \\
\hline & Gansu & 0.45397 & 0.44661 & 0.43034 & \\
\hline & Qinghai & 0.34314 & 0.29427 & 0.28676 & \\
\hline & Ningxia & 0.26843 & 0.27363 & 0.27389 & \\
\hline & Xinjiang & 0.42799 & 0.37705 & 0.33856 & \\
\hline
\end{tabular}

Energy Saving and Waste Reduction Potential Analysis. Table 2 is result of the energy saving and waste reduction potential analysis. Overall, the average potential wastewater, waste gas and industrial solid waste emission reduction of China's provinces are 146.1017 million tons, 266.280 thousand tons and 52.5173 million tons, and the potential energy saving is 32.3596 tons. The correlation value between potential wastewater reduction and energy saving is -0.0193, which means there is little relationship between wastewater reduction and energy saving. In contrast, the correlation values between potential waste gas reduction and energy saving and between industrial solid waste reduction and energy saving are 0.8648 and 0.8013 respectively. Therefore, despite the benefits of abate wastewater, it is not the key access to improve energy efficiency, while controlling the undesirable output, waste gas and industrial solid wastes, to the author's conjecture, are able to save energy consumption effectively.

From a perspective of area, the author analyzes the energy saving and waste reduction potential in 2012 of which the results are shown in Table 2. As can be seen, the energy saving potential of the western and eastern area is minimal-average energy saving amount is 29.5995 and 30.5758 million tons of SCE respectively. Central area's energy saving and waste reduction potential are considerable, with wastewater reduction for 294.6550 million tons, waste gas for 303.06 thousand tons, industrial solid waste for 61.8274 million tons and energy saving for 40.2300 million tons of SCE. Therefore, to 
reduce energy consumption and reduce waste emissions the country could focus on the central area firstly.

Table 2 Average Reduction and Energy Saving by Area in 2012 (10 000 tons)

\begin{tabular}{cccc}
\hline Wastewater & Waste Gas & Industrial Solid Wastes & Energy Saving \\
\hline 4277.3545 & 19.7740 & 5904.0279 & 3057.5803 \\
29465.5043 & 30.3306 & 6182.7448 & 4023.0066 \\
12891.0273 & 30.4749 & 4344.4662 & 2959.9466 \\
\hline
\end{tabular}

\section{Conclusion}

This paper describes the relationship between energy issue, environmental issues and economic development, and suggests the importance for China to find a balance of the three issues. This paper also points out the practical significance of the research on energy efficiency calculation and reduction potential in China to develop energy saving and waste abatement targets and implement. Then the paper discusses the current research and the deficiency, and points out research methodology of this article.

Based on scrutiny of the advantages and disadvantages of current improved model of non-desired output efficiency calculation, this paper choose SBM-DEA model as energy efficiency measurement. In addition, provincial and municipal energy efficiency differences are considerable, presenting a "top as aggregation, the higher part as rareness and lower part as majority" shape. In addition, from regional perspective, the eastern area has the highest energy efficiency; the lowest located in western area; and central area has greatest waste reduction potential.

In conclusion, comprehensive analysis shows that starting reducing pollutants from the central area would have obvious effects and also be more feasible on the economy. However, for Shanghai, Beijing, Tianjin, Guangdong, Liaoning and Jiangsu whose energy efficiencies have reached 1.00 and the reduction abatement is minimal, energy saving would contribute little in the future.

\section{Acknowledgement}

This research was financially supported by Creative Activity Plan for College Students (B. 05-0115-14-103), named “Regional Energy Efficiency and Factor Analysis”.

\section{Reference}

[1] United Nations Environment Programme. “UNEP Annual Report 2013”, UNEP, (2013).

[2] M. G. Patterson, What is energy efficiency? Concepts, indicators, and methodological issues, J. Energy Policy. 24 (1996) p. 377-390.

[3] W. W. Cooper and K. Tone, Measures of inefficiency in data envelopment analysis and stochastic frontier estimation, J. European Journal of Operational Research. 99 (1997) p. 72-88.

[4] A. Charnes, Measuring the Efficiency of Decision-Making Units, J. European Journal of Operational Research. 3 (1979) p. 339.

[5] J. Hu and S. Wang, Total-factor energy efficiency of regions in China, J. Energy Policy. 34 (2006) p. 3206-3217.

[6] K. Wang and Y. Wei, China's regional industrial energy efficiency and carbon emissions abatement costs, J. Applied Energy. 130 (2014) p. 617-631.

[7] Y. Choi, N. Zhang and P. Zhou, Efficiency and abatement costs of energy-related co2 emissions in china: a slacks-based efficiency measure, J. Applied Energy. 98 (2012) p. 198-208.

[8] C. Wei, J. Ni and L. Du, Regional allocation of carbon dioxide abatement in China, J. China Economic Review. 23 (2012) p. 552-565.

[9] K. Tone, A slacks-based measure of efficiency in data envelopment analysis, J. European Journal of Operational Research. 130 (2001) p. 498-509. 